\title{
Some peculiarities of the pulmonary phagocytotic response: dust retention kinetics and silicosis development during long term exposure of rats to high quartz dust levels
}

\author{
L I PRIVALOVA, B A KATSNELSON, L N YELNICHNYKH
}

\begin{abstract}
From the Institute of Industrial Hygiene and Occupational Diseases, Laboratory of Experimental Pneumoconioses, Sverdlovsk, 620014 USSR
\end{abstract}

ABSTRACT Rats were exposed to quartz dust (about $90 \mathrm{mg} / \mathrm{m}^{3}$ ) for five hours a day, five times a week in $_{\infty}^{\text {N }}$ either throughout the 48 weeks of the experiment or for a total of 40 weeks plus eight weeks of "rest." Cytological study of bronchoalveolar lavage showed that at a certain level of silicotic changes in the ${ }_{-}^{\supset}$ lungs, a pronounced breakdown in pulmonary dust clearance by macrophages could be observed. $\rightarrow$ There was, however, a concomitant compensatory increase in the contribution to pulmonary?. phagocytosis by the neutrophil leukocytes (NL). As a result, pulmonary dust kinetics could be $\vec{\bullet}$ mathematically described using a constant clearance rate both throughout the 48 weeks of exposure and during the eight weeks after the end of the 40 week exposure. It is shown in a separate experiment that enhanced recruitment of NL into the airways may be due not only to an attractant effect of the $\sum_{\Sigma}^{\circ}$ products of macrophage breakdown (PMB) themselves but also to the release of an NL attractant factor by viable macrophages activated under influence of the PMB.

It is beyond doubt that recruitment of phagocytosing cells to the free surface of the lower airways plays a key part in the elimination of deposited particles to the zone of efficient mucociliary transport and thus precludes their penetration into fixed lung tissues and translocation to lymph nodes. It was shown earlier that not only alveolar macrophages (AM) but neutrophil leukocytes (NL) contribute significantly to dust elimination and that recruitment of both cell types is regulated, first of all, through a complex self regulating mechanism. ${ }^{12}$ The main feature of the latter is its dependence on the amount of lipid containing products of macrophage breakdown (PMB), this in turn depending on the level of dust exposure and the cytotoxicity of the dust particles. This self regulation, however, acts in accordance with the host's general reactivity and is influenced by neurohormonal regulation. $^{2}$

Whether alterations in the operation of the phagocytotic mechanism of pulmonary dust clearance occur after long term exposure to dust is far less well known, nor is it known to what degree the kinetics of pulmonary dust retention may be changed as the result of

Accepted 13 May 1986 chronic damage to this mechanism. Having found no흘 differences in kinetics of quartz dust retention in lungs after long term exposure to different dust levels ( 1.0 v $20.0 \mathrm{mg} / \mathrm{m}^{3}$ ), Stöber et al nevertheless admitted the possibility of a breakdown in the pulmonary clearance ${ }_{\odot}^{\circ}$ mechanisms with a sufficiently large dust burden. ${ }^{3}$ A 3 team of investigators from the Edinburgh Institute of Occupational Medicine, having studied the kinetics of - . pulmonary retention of amosite fibres, supposed thatô exactly such a breakdown was observed at a certain level of retention and connected it with a "dust over-o load" of the lungs. ${ }^{45}$ They expressed the opinion that it was the macrophageal mechanism of pulmonary․ㅡ. dust clearance that suffered from such an overload. $\bar{N}$ We became interested in the question of whether the. pulmonary phagocytotic response to a continuous $\tilde{O}^{-}$ dust exposure at a constant level really undergoes any స్ట unfavourable changes and whether there are anyo shifts in the dust retention kinetics corresponding too such changes. It seemed natural to study this problem, first of all, in relation to silica dust, which exerts the most prominent damaging influence on the macro- $\square$ phage, and to provide both a high level of dusto exposure and a sufficiently long (in terms of the life- $\frac{\mathbb{Q}}{\mathrm{Q}}$ span of the rat) exposure period. 
As the results of such experiments showed once more the most important role of the recruitment to the airways of NLs, we consider here also some new experimental data concerning the mechanisms controlling this recruitment.

\section{Materials and methods}

The inhalation experiment was carried out on male white rats with an original body weight of about $160 \mathrm{~g}$. They were exposed to dust generated by milled quartzite rock from one of the Urals deposits which was more than $95 \%$ alpha-quartz. Samples of airborne dust from the exposure chambers had, on average, a particle size distribution (under light microscopy with magnification $\times 900$ ) as follows: $0-1 \mu \mathrm{m}$ : $51 \cdot 3 \%,>1-2 \mu \mathrm{m}: 33 \cdot 1 \%,>2-5 \mu \mathrm{m}: 12 \cdot 0 \%,>5 \mu \mathrm{m}:$ $3.6 \%$. The animals were exposed for five hours a day, five times a week for 48 weeks, the average dust concentration for this period being $87.8 \pm 3.4 \mathrm{mg} / \mathrm{m}^{3}$ (mean $\pm \mathrm{SE}$ ). Some 10-11 rats from the exposed and control groups were killed after 10,20 , and 40 weeks from the start of the experiment; the average dust concentrations for these periods were $87 \cdot 3 \pm 3 \cdot 8,84 \cdot 9$ \pm 6.3 , and $85.4 \pm 3.7 \mathrm{mg} / \mathrm{m}^{3}$ respectively. Moreover, in the same dust chambers were rats for whom the total exposure was only $\mathbf{4 0}$ weeks, with three different patterns of distribution in the period between the beginning and the end of the 48 week experiment: (a) first 40 weeks of exposure and then eight weeks out of the dust chamber ("the rest"); (b) 20 weeks of exposure, then eight weeks of rest and 20 weeks more of exposure; (c) four subperiods of 12 weeks each comprising 10 weeks of exposure and two weeks of rest, which two weeks completed each of the first three subperiods, whereas in the fourth the rest was given in the 10th and 11th weeks and the exposure was resumed during the 12 th week. The mean dust concentrations for the total 40 weeks of exposure were, respectively, $85.4 \pm 3.7,89.7 \pm 4.0$, and $87.5 \pm$ $3.8 \mathrm{mg} / \mathrm{m}^{3}$.

Forty eight weeks after the beginning of the experiment all surviving rats were simultaneously killed (in each of four exposed groups as well as in the unexposed ones there were 18-21 surviving animals). Both in these rats and in those killed at the above mentioned intermediate stages of the weekly exposure period we determined

(1) the total cell count of single bronchoalveolar lavage (BAL) according to LaBelle and Brieger ${ }^{6}$ with differential counting of cells in smears of centrifuged BAL sediments;

(2) the dry weight of the lungs and the wet and dry weights of the tracheobronchial (TB) lymph nodes;

(3) total lipid, ${ }^{7}$ total hydroxyproline,${ }^{8}$ and dust $^{9}$ content of the lungs.
Partly to eliminate the variability of the indices connected with the variability of body weight, not only the weight of the organs but also their lipid and hydroxyproline content were related to $100 \mathrm{~g}$ body weight. $^{8}$

The lungs and TB lymph nodes from several rats killed at the end of the experiment were taken for histological study under the light microscope using a haematoxylin-eosin and van Gieson stains.

An additional experiment was performed on female Wistar rats to test the part taken by the activation of viable macrophages with PMB in the attraction of NLs to the lower airways. Macrophages were obtained from the peritoneal cavity of rats $\mathbf{4 8}$ hours after intraperitoneal injection of sterile mineral oil. PMB were produced with a triple freezing-thawing procedure as described earlier. ${ }^{1}$ Peritoneal macrophages having $97 \%$ viability in the trypan-blue exclusion test were incubated for three hours at $37^{\circ} \mathrm{C}(a)$ in 199 medium or $(b)$ in the same medium plus either PMB in a dose corresponding to $2 \cdot 10^{6}$ broken down cells per $\mathrm{ml}$, or zymosan in final concentration $0.05 \mathrm{mg} / \mathrm{ml}$. In a separate sample of 199 medium, PMB without viable macrophages were similarly incubated. Each sample was then centrifuged at $1500 \mathrm{rpm}$ for 30 minutes at $4^{\circ} \mathrm{C}$, and $1 \mathrm{ml}$ of the supernatant was instilled intratracheally into a rat. From eight to 10 recipient rats were given supernatants obtained after each variant of the incubation or control medium.

A single bronchoalveolar lavage was performed under hexobarbitone anaesthesia after 24 hours for total and differential cell counts as mentioned above.

\section{Results}

Histological investigation of the lungs showed, in rats exposed throughout the 48 weeks, typical silicotic nodules up to the second maturity stage ${ }^{10}$ and also large foci of alveolar lipoproteinosis with pronounced collagen fibrosis of adjacent interalveolar septa; pronounced hyperplasia of peribronchial lymph follicles with the development of focal reticuloendothelial cell hyperplasia (this was also found in TB lymph nodes); goblet cell hyperplasia in bronchial mucosa. Lungs of rats exposed uninterruptedly during the first 40 weeks and killed after eight weeks of rest showed virtually the same histological picture. When the exposure period had been divided into four equal parts each comprising 10 weeks of exposure and two weeks of rest, silicotic nodules of the first stage predominated. Still less pronounced were the nodular lesions (with complete absence of silicotic nodules in some rats' lungs) in the group which had been given eight weeks rest in the middle of the exposure period.

The group averages of all indices mentioned in the 
materials and methods section are presented in tables $1-5$ and in the figure.

\section{Discussion}

As clearly seen from table 1, recruitment of AMs to the airways changed considerably during the 48 weeks of dust exposure. If the difference between AM counts in BAL of exposed and control rats is taken as a measure of the response to the deposition of inhaled silica particles this response appears to be vigorous only in the first half of the period. At the end of the 10 th week the difference was $1.45 \pm 0.32 \times 10^{6}$ (p < 0.05 ), and at the end of the 20th week it was still greater: $3.15 \pm 0.62 \times 10^{6}(\mathrm{p}<0.05)$. After 20 more weeks of exposure, however, this difference disappeared completely, while at the end of the 48th week it was small and statistically non-significant $(0.30 \pm$ $\left.0.42 \times 10^{6}\right)$. The decrease between the 20th and 48th weeks of exposure is highly significant $(p<0.01)$. These results seem to corroborate the hypothesis that there is a breakdown in the macrophageal pulmonary dust clearance mechanism.

As seen in the figure, the pulmonary dust retention kinetics may be approximated to a monoexponential function $\left(y=21-17 \mathrm{e}^{-0.0783}\right.$, where " $\mathrm{t}$ " is time in weeks). In other words, the region of the respiratory tract where this long term retention takes place might be described using a one compartment model with constant rates of deposition (1.6443 mg a week) and of elimination $\left(k=0.0783 \mathrm{wk}^{-1}\right)$. Such a conclusion accords well with results of other experiments with quartz dust inhalation, and closely approximates calculated model parameters. In experiments conducted on rats exposed to dust levels of either 1.0 or
$20.0 \mathrm{mg} / \mathrm{m}^{3}$ Stöber et al found that the pulmonary region clearance rate was, respectively, $7.4 \times 10^{-3} \stackrel{3}{\circ}$ and $9.0 \times 10^{-3}$ for one exposure - that is, 0.0518 and $0.063 \mathrm{wk}^{-1}{ }^{3}$ Taking into account the inevitable vari-? ability of biological factors (conditions of housing and feeding, age difference, and so on) and probable differences between quartz samples used in different $\frac{\bar{s}}{\widetilde{T}}$. experiments, the latter two estimates differ little from ours. Moreover, the trend of the values suggests ane increase in the clearance rate with an increase in dust. exposure levels.

In our experiment the efficiency of pulmonary dust $\vec{\omega}$ clearance also remained constant in the postexposureo period despite the obvious complete failure of the macrophageal clearance mechanism at the end of $40 \mathrm{~B}$ weeks exposure. Indeed, a group of rats was allowed to "rest" after such exposure and was killed eightp weeks later. Dust retention to the end of the 40th week computed from the above mentioned equationo $(20.25 \mathrm{mg})$ is close to the value actually found in the lungs of rats killed at that time $(19.4 \pm 1.7 \mathrm{mg})$ and may therefore be used as the starting lung burden $\left(\mathrm{x}_{0}\right)$ for calculating dust elimination during the eight: postexposure weeks according to the equation $\vec{t}$ $\mathrm{Y}=\mathrm{x}_{0} \mathrm{e}^{-\mathrm{kt}}$. If we assume that the constant clearance rate is the same as in the period of dust accumulation $\left(\mathrm{k}=0.0783 \mathrm{wk}^{-1}\right)$, the residual amount of dust in theo lungs would be $10.82 \mathrm{mg}$. This value lies near the lower $95 \%$ confidence limit of the actual mean dus content of lungs in rats from the group surviving eighp weeks after 40 weeks exposure $(12.7 \pm 1.0 \mathrm{mg}, 95 \%$ confidence limits being $10.6-14.8 \mathrm{mg})$. This should $\overrightarrow{5}$ be considered as a satisfactory confirmation of the mathematical prediction and, at any rate, does not confirm the hypothesis according to which, post exposure elimination of dust accumulated in lungso

Table 1 Main cytological characteristics of bronchoalveolar lavage (BAL) of rats exposed for up to 48 weeks to quartz dust inhalation (five hours a day, five times a week) and of control rats $(\bar{X} \pm S \bar{x})$

\begin{tabular}{|c|c|c|c|c|c|c|}
\hline \multirow{2}{*}{$\begin{array}{l}\text { Duration of } \\
\text { experiment } \\
\text { (weeks) }\end{array}$} & \multirow[b]{2}{*}{$\begin{array}{l}\text { Group of } \\
\text { rats }\end{array}$} & \multicolumn{3}{|c|}{ No of cells in $B A L \times 10^{6}$} & \multicolumn{2}{|c|}{ Coefficient $N L / A M$} \\
\hline & & Total & $\begin{array}{l}\text { Alveolar macrophages } \\
(A M)\end{array}$ & $\begin{array}{l}\text { Neutrophil leukocytes } \\
(N L)\end{array}$ & In group & $\begin{array}{l}\text { Exposed to control } \\
\text { ratio }\end{array}$ \\
\hline 10 & $\begin{array}{l}\text { Control } \\
\text { Exposed }\end{array}$ & $\begin{array}{r}1.64 \pm 0.16 \\
3.3 \pm 0.34^{0}\end{array}$ & $\begin{array}{l}1 \cdot 26 \pm 0 \cdot 13 \\
2 \cdot 71 \pm 0 \cdot 29^{+}\end{array}$ & $\begin{array}{l}0.06 \pm 0.01 \\
0.39 \pm 0.09^{+}\end{array}$ & $\begin{array}{c}0.049 \pm 0.007 \\
0.143 \pm 0.029+\end{array}$ & $\overline{2.92} \pm 0.74$ \\
\hline 20 & $\begin{array}{l}\text { Control } \\
\text { Exposed }\end{array}$ & $\begin{array}{l}1.91 \pm 0.20 \\
6.95 \pm 0.86^{\circ} \S\end{array}$ & $\begin{array}{l}1.62 \pm 0.03 \\
4.77 \pm 0.62^{\circ} \S\end{array}$ & $\begin{array}{l}0.10 \pm 0.02 \\
1.50 \pm 0.30^{\circ} \xi\end{array}$ & $\begin{array}{l}0.063 \pm 0.010 \\
0.315 \pm 0.51^{x_{\S}}\end{array}$ & $\overline{5} \cdot 04 \pm 1 \cdot 15$ \\
\hline 40 & $\begin{array}{l}\text { Control } \\
\text { Exposed }\end{array}$ & $\begin{array}{l}3.22 \pm 0.43 \\
7.65 \pm 1.05^{\mathrm{x}}\end{array}$ & $\begin{array}{l}2.59 \pm 0.36 \\
2.58 \pm 0.39\end{array}$ & $\begin{array}{l}0.47 \pm 0.10 \\
4.66 \pm 0.67^{\circ} g^{!}\end{array}$ & $\begin{array}{l}0.183 \pm 0.030 \\
1.807 \pm 0.138^{\circ} \S !\end{array}$ & $\overline{9} \cdot 87 \pm 1 \cdot 79 \S^{!}$ \\
\hline 48 & $\begin{array}{l}\text { Control } \\
\text { Exposed }\end{array}$ & $\begin{array}{l}2.48 \pm 0.22 \\
8.02 \pm 1.00^{\circ !}\end{array}$ & $\begin{array}{l}1.99 \pm 0.19 \\
2.29 \pm 0.37\end{array}$ & $\begin{array}{l}0.35 \pm 0.07 \\
5.06 \pm 0.68^{\circ !}\end{array}$ & $\begin{array}{l}0.178 \pm 0.032 \\
2.214 \pm 0.257^{\circ 1}\end{array}$ & $\overline{12} \cdot 44 \pm 2 \cdot 66^{!}$ \\
\hline
\end{tabular}

${ }^{+} x^{x}$ and $^{\circ}$ Values of exposed group which differ with statistical significance (with p, correspondingly, $<0.05,<0.01$, and $<0.001$ ) from those $\tau$ of controls.

$\S$ Statistically significant difference between a given value for the exposed group and a corresponding value for the exposed rats killed at the preceding moment $(\mathrm{p}<0.05)$.

!Values significantly $(p<0.05)$ different from corresponding values of the 10 week exposure group. 
is considerably slowed down as a result of a long term retention.

Thus for describing the kinetics both of quartz dust accumulation in the lungs of the rat and of its subsequent clearance, even when exposure and postexposure periods are long enough and the exposure level is high, one obviously does not need to resort either to an "overload" model or to a "sequestration" model as proposed ${ }^{5}$ for describing the pulmonary kinetics of amosite. Nevertheless, how can one reconcile such a conclusion with clear evidence of a deficiency in the recruitment of AMs?

As is evident from the table 1 , the recruitment of NLs to the airways of rats exposed to quartz dust during 48 weeks steadily increased. This was shown by the increase in the absolute NL count and in the NL/AM ratio. In control rats this ratio, although not increasing at the same rate, was higher in the second half of the experimental period than during the first $\mathbf{2 0}$ weeks. Therefore we used an additional index: the rátio of the NL/AM coefficient in an exposed group to that in the corresponding control. This index also increased throughout the $\mathbf{4 8}$ week exposure period.

We have already shown that the enhanced recruitment of NLs by a cytotoxic dust, or by an imitation of its action-for example, by combining exposure to particles of low cytotoxicity with intratracheal instillation of PMB - ensures the phagocytosis of a large number of particles comparable with, and sometimes even equal to, that of particles engulfed by AMs. ${ }^{1}$ We repeatedly emphasised in this connection that the NL response of the lower airways to the deposition of silica and other cytotoxic particles must be regarded not simply as a pathological reaction ("inflammation") but as an important compensatory one, maintaining the high efficiency of pulmonary clearance. We emphasised that this auxiliary clearance mechanism is resorted to when the main

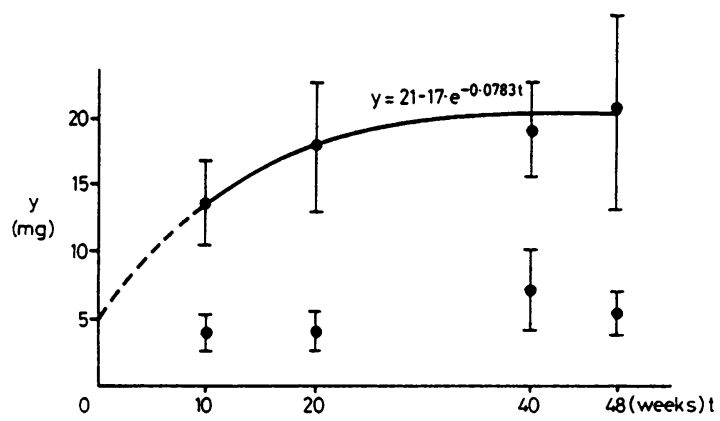

Kinetics of pulmonary dust retention during 48 weeks exposure according to experimental data (average values and $95 \%$ confidence limits) and a mathematical model (curve and equation). Upper points correspond to exposed, lower points to control rats.

clearance mechanism (AMs recruitment and phagocytosis) is damaged, and operates as a dose dependent response to the products of AM breakdown. ${ }^{12}$ The results of the present experiment seem to corroborate this concept and, moreover, show that the compensation under discussion may be adequate. In fact, it would be difficult to propose another explanation for the persistence of a constant dust clearance rate against the background of the considerable damage caused to the AMs role in pulmonary phagocytosis.

There are several arguments against considering both this damage and the compensatory increase in the NLs' contribution to the phagocytotic response of the airways as a direct consequence of pulmonary dust overload. Indeed the amount of dust retained in lung tissue increased most during the first half of the exposure period (cf table 2 and the figure), whereas recruitment of AMs not only did not stop between the

Table 2 Some quantitative indices of the state of lungs and TB lymph nodes of rats exposed for up to 48 weeks to quartz dust inhalationo (five hours a day, five times a week) and of control rats $\left(\bar{X} \pm S_{\bar{x}}\right)$

\begin{tabular}{|c|c|c|c|c|c|c|}
\hline \multirow{2}{*}{$\begin{array}{l}\text { Duration of } \\
\text { experiment } \\
\text { (weeks) }\end{array}$} & \multirow[b]{2}{*}{$\begin{array}{l}\text { Group of } \\
\text { rats }\end{array}$} & \multirow[b]{2}{*}{$\begin{array}{l}\text { Dry weight of lungs } \\
\text { (mg/100g body weight) }\end{array}$} & \multirow{2}{*}{$\begin{array}{l}\text { Dry weight of } T B \text { lymph } \\
\text { nodes }(\mathrm{mg} / 100 \mathrm{~g} \text { body } \\
\text { weight })\end{array}$} & \multicolumn{3}{|l|}{ Lungs } \\
\hline & & & & $\begin{array}{l}\text { Hydroxyproline content } \\
\text { ( } \mathrm{g} / 100 \mathrm{~g} \text { body weight })\end{array}$ & $\begin{array}{l}\text { Lipid content } \\
(\mu \mathrm{g} / 100 \mathrm{~g} \text { body weight })\end{array}$ & $\begin{array}{l}\text { Dust content } \\
\text { (mg) }\end{array}$ \\
\hline 10 & $\begin{array}{l}\text { Control } \\
\text { Exposed }\end{array}$ & $\begin{array}{l}110 \cdot 8 \pm 10 \cdot 0 \\
107 \cdot 4 \pm 4 \cdot 9\end{array}$ & $\begin{array}{l}6.5 \pm 1 \cdot 6 \\
9 \cdot 2 \pm 1.6\end{array}$ & $\begin{array}{l}1316 \pm 128 \\
1317 \pm 73\end{array}$ & $\begin{array}{l}11 \cdot 3 \pm 0.6 \\
11.7 \pm 0.6\end{array}$ & $\begin{array}{c}3.8 \pm 0.5 \\
13 \cdot 7 \pm 1 \cdot 7^{+}\end{array}$ \\
\hline 20 & $\begin{array}{l}\text { Control } \\
\text { Exposed }\end{array}$ & $\begin{array}{l}95.4 \pm 5.9 \\
177 \cdot 0 \pm 10 \cdot 2^{\circ} \S\end{array}$ & $\begin{array}{l}7 \cdot 1 \pm 0 \cdot 6 \\
27 \cdot 1 \pm 2 \cdot 4^{\circ} \S\end{array}$ & $\begin{array}{l}1128 \pm 57 \\
1592 \pm 89^{\circ} \S\end{array}$ & $\begin{array}{l}11 \cdot 1 \pm 0.5 \\
44 \cdot 9 \pm 4 \cdot 0 \% 8\end{array}$ & $\begin{array}{c}4 \cdot 1 \pm 0 \cdot 6 \\
16 \cdot 9 \pm 2 \cdot 2^{\circ}\end{array}$ \\
\hline $4 r$ & $\begin{array}{l}\text { Control } \\
\text { Exposed }\end{array}$ & $\begin{array}{l}110 \cdot 0 \pm 5 \cdot 9 \\
224 \cdot 9 \pm 15 \cdot 7 \circ 8 !\end{array}$ & $\begin{array}{l}6 \cdot 1 \pm 0 \cdot 7 \\
30 \cdot 8 \pm 1 \cdot 5^{\circ} !\end{array}$ & $\begin{array}{c}949 \pm 80 \\
2114 \pm 204^{\circ} \xi !\end{array}$ & $\begin{array}{l}14 \cdot 1 \pm 0.6 \\
52 \cdot 0 \pm 3 \cdot 2^{\circ !}\end{array}$ & $\begin{array}{r}7 \cdot 4 \pm 1 \cdot 2 \S ! \\
19 \cdot 4 \pm 1 \cdot 7^{\circ !} !\end{array}$ \\
\hline 48 & $\begin{array}{l}\text { Control } \\
\text { Exposed }\end{array}$ & $\begin{array}{c}98 \cdot 6 \pm 4 \cdot 1 \\
275 \cdot 8 \pm 10 \cdot 5 \% !\end{array}$ & $\begin{array}{l}7 \cdot 1 \pm 0 \cdot 5 \\
39 \cdot 2 \pm 1 \cdot 2^{\circ} \S !\end{array}$ & $\begin{array}{l}1010 \pm 36 \\
2426 \pm 106^{\circ} !\end{array}$ & $\begin{array}{l}12 \cdot 9 \pm 0.6 \\
67 \cdot 2 \pm 0.4 \% 8 !\end{array}$ & $\begin{array}{c}5 \cdot 7 \pm 0 \cdot 8 \\
20 \cdot 8 \pm 3 \cdot 4^{\circ} !\end{array}$ \\
\hline
\end{tabular}

Notation of statistical significance as in table 1 . 
10 th and 20 th weeks but was increasing at a greater rate. On the other hand, the most complete breakdown of the macrophage clearance mechanism occurred between the 20th and 40th weeks, when pulmonary dust retention had reached its equilibrium level according to both theoretical considerations (cf the curve shown in the figure) and experimental data (cf the figure and table 2). Moreover, the recruitment of NLs increased up to the end of the exposure period, although the dust overload of the lungs remained the same as eight weeks earlier.

We suppose that all the shifts in the BAL cell counts we observed are due to the development of a pulmonary pathological process-silicosis. The severity of the latter, in its turn, depends not only on the mass of accumulated dust (pulmonary dust burden) but also on the time of its action on the lung tissues. We have shown that as a fairly adequate criterion for the mathematical prediction of this severity one may use the value of the definite integral of a function describing pulmonary dust retention, the limits of integration being the onset of exposure and any chosen moment for which the prediction is made. ${ }^{11}$ Below we shall refer to this criterion as the "action integral" (AI).

As seen in table 2, the weight of the lungs and their lipid and hydroxyproline contents in the exposed group did not differ from those in the control group up to the 10th week. Thus it would be justifiable to consider the shift of BAL cellularity observed to the end of the 10th week as a "normal" defensive response of virtually healthy lungs to the deposition of highly cytotoxic dust particles. Ten weeks later, however, the lungs were clearly silicotic and after 40 weeks of exposure the pathological changes were even more pronounced. It was then that the cellular composition of the BAL was most dramatically changed. At the end of the 48 week exposure period, the severity of the silicotic process reached a still higher level, the earlier attained "plateau" of dust retention notwithstanding (which fact is in agreement with the continuing increase of the AI), and the NL count in the BAL also reached a still higher level.

Some additional arguments supporting the above conjectures may be gained by comparing experimental data related to rats exposed during 48 weeks with those related to the two groups of rats whose BAL was also studied 48 weeks after the beginning of the experiment but who had been exposed to dust for only $\mathbf{4 0}$ weeks in all. One of these groups was given two 20 week exposures with an eight week interval (rest), whereas for the other, the whole experimental period was divided into four subperiods, each comprising 10 weeks of exposure and two weeks of rest. In order to make the conditions of the BAL examination in all three groups comparable, the fourth subperiod was arranged so that the killing of the rats in this group was preceded not by a prolonged rest but by a week of every day exposure (see the section on materials and methods.)

As seen from table 3, when the interval of exposure was put in the middle of the experimental period, recruitment of AMs was the highest and recruitment of NLs the lowest of all groups under discussion. The amount of dust retained in the lungs of these rats did not differ significantly from that in the rats which had been exposed throughout the 48 week period; it was somewhat lower, in fact (see table 4). On the other hand, it was somewhat greater compared with that which accumulated in the lungs after the four ten week exposures, although the cytological characteristics of the BAL after this exposure were similar to those observed after the uninterrupted 48 week exposure. Both the histological picture of silicosis and the quantitative indices of its severity (shown in table 4) were minimal in the group with the eight week interval

Table 3 Main cytological characteristics of bronchoalveolar lavage (BAL) of exposed and control rats to the end of the 48 week experimental period with different patterns of exposure $\left(\bar{X} \pm S_{\bar{x}}\right)$

\begin{tabular}{|c|c|c|c|c|c|}
\hline \multirow[b]{2}{*}{ Exposure pattern } & \multicolumn{3}{|c|}{ No of cells in $B A L \times 10^{6}$} & \multicolumn{2}{|c|}{ Coefficient $N L / A M$} \\
\hline & Total & $\begin{array}{l}\text { Alveolar macrophages } \\
(A M)\end{array}$ & $\begin{array}{l}\text { Neutrophil leukocytes } \\
(N L)\end{array}$ & In group & $\begin{array}{l}\text { Exposed to control } \\
\text { ratio }\end{array}$ \\
\hline No exposure (control) & $2 \cdot 48 \pm 0 \cdot 22$ & $1.99 \pm 0.19$ & $0.35 \pm 0.07$ & $0.178 \pm 0.032$ & - \\
\hline $\begin{array}{l}48 \text { weeks of constant } \\
\text { exposure }\end{array}$ & $8.02 \pm 1.00^{\circ}$ & $2 \cdot 29 \pm 0.37$ & $5.06 \pm 0.68^{\circ}$ & $2 \cdot 214 \pm 0 \cdot 257^{\circ}$ & $12 \cdot 44 \pm 2 \cdot 66$ \\
\hline $\begin{array}{l}20 \text { weeks of exposure } \\
+8 \text { weeks of rest }+20 \\
\text { weeks of exposure }\end{array}$ & $7.75 \pm 0.73^{\circ}$ & $3.34 \pm 0.44^{+}$ & $3.76 \pm 0.47^{\circ}$ & $1 \cdot 125 \pm 0.138^{\circ} \S$ & $6 \cdot 32 \pm 1 \cdot 38 \S$ \\
\hline $\begin{array}{l}\text { Four subperiods, each } \\
\text { comprising } 10 \text { weeks of } \\
\text { exposure }+2 \text { weeks of rest }\end{array}$ & $7 \cdot 49 \pm 0.83^{\circ}$ & $2.32 \pm 0.44$ & $4.28 \pm 0.56^{\circ}$ & $1.840 \pm 0.312^{\circ}$ & $10 \cdot 34 \pm 2.56$ \\
\hline
\end{tabular}

Notation of statistical significance of differences between exposed and control groups as in table 1. 
Table 4 Some quantitative indices of the state of lungs and TB lymph nodes of exposed and control rats at the end of the 48 week experimental period with different patterns of exposure $\left(\bar{X} \pm S_{\bar{x}}\right)$

\begin{tabular}{|c|c|c|c|c|c|}
\hline \multirow[b]{2}{*}{ Exposure pattern } & \multirow[b]{2}{*}{$\begin{array}{l}\text { Dry weight of lungs } \\
(\mathrm{mg} / 100 \mathrm{~g} \text { body weight })\end{array}$} & \multirow{2}{*}{$\begin{array}{l}\text { Dry weight of } T B \\
\text { lymph nodes } \\
(\mathrm{mg} / 100 \mathrm{~g} \text { body weight })\end{array}$} & \multicolumn{3}{|l|}{ Lungs } \\
\hline & & & $\begin{array}{l}\text { Hydroxyproline content } \\
(\mu \mathrm{g} / \mathrm{l} 00 \mathrm{~g} \text { body weight })\end{array}$ & $\begin{array}{l}\text { Lipid content } \\
(\mathrm{mg} / 100 \mathrm{~g} \text { body weight })\end{array}$ & $\begin{array}{l}\text { Dust } \\
\text { content }(m g \text { 恶 }\end{array}$ \\
\hline No exposure (control) & $98 \cdot 6 \pm 4 \cdot 1$ & $7 \cdot 1 \pm 0 \cdot 5$ & $1010 \pm 36$ & $12 \cdot 9 \pm 0.6$ & $5.7 \pm 0.8$ \\
\hline $\begin{array}{l}48 \text { weeks of constant } \\
\text { exposure }\end{array}$ & $294 \cdot 7 \pm 14 \cdot 5^{\circ}$ & $39 \cdot 2 \pm 1 \cdot 2^{\circ}$ & $2426 \pm 106^{\circ}$ & $67 \cdot 2 \pm 0.4^{\circ} \S$ & $20 \cdot 8 \pm 3 \cdot 4^{\circ}$ \\
\hline $\begin{array}{l}20 \text { weeks of exposure }+8 \\
\text { weeks of rest }+20 \text { weeks } \\
\text { of exposure }\end{array}$ & $218 \cdot 9 \pm 7 \cdot 2^{\circ} \S$ & $29 \cdot 1 \pm 3 \cdot 0^{\circ} \S$ & $1893 \pm 73^{\circ} \S$ & $48 \cdot 7 \pm 3 \cdot 1^{\circ} \S$ & $16 \cdot 1 \pm 2 \cdot 1^{\circ} \frac{\omega}{\sigma}$ \\
\hline $\begin{array}{l}\text { Four subperiods each com } \\
10 \text { weeks of exposure }+2 \\
\text { weeks of rest }\end{array}$ & $\begin{array}{l}\text { ising } \\
255 \cdot 5 \pm 10 \cdot 4^{\circ} \S\end{array}$ & $26 \cdot 0 \pm 1 \cdot 5^{\circ} \S$ & $2114 \pm 115^{\circ} \S$ & $54 \cdot 1 \pm 4 \cdot 1^{\circ}$ & $12 \cdot 7 \pm 1 \cdot 0^{\circ} \S$ \\
\hline
\end{tabular}

between exposures.

The above mentioned mathematical analysis ${ }^{11}$ can explain this apparent paradox. It was shown that, when total time of exposure subperiods and of rest subperiods are fixed, varying the pattern of their arrangement may decrease the action integral value and increase of the amount of dust retained by lungs only to the moment corresponding to the upper limit of integration - that is, to the moment of estimation of all pulmonary changes. When the AI is taken with limits from zero time to the end of the 48th week, one obtains the following values: $670 \mathrm{mg} / \mathrm{wk}$ for the group with one eight week interval in the middle of the period and $690 \mathrm{mg} / \mathrm{wk}$ for the group with periodic exposure. Hence, it is just in the first group that one would expect to find a lower intensity of pathological changes and a higher final dust retention.

For one more group used in our experimentnamely, for that given the same eight weeks of rest just before killing (after 40 weeks of uninterrupted exposure)-the computed AI value equals $753 \mathrm{mg} / \mathrm{wk}$. In this group the severity of silicosis differed little from that in the group exposed throughout all 48 weeks and for which the AI is $795 \mathrm{mg} / \mathrm{wk}$, although in the former postexposure elimination of dust had been significant (as was shown above). In other words, the severity was higher than in the two other groups with a total of $\mathbf{4 0}$ weeks exposure. (For example, dry weight of lungs and TB lymph nodes in this group were, respectively, $164.3 \pm 13.3$ and $34.1 \pm 2.6$ per $100 \mathrm{~g}$ body weightfor corresponding data for other groups see table 4 . Bearing in mind the long time lag between the last exposure of these rats and their killing, we have not studied BAL in this group as the results of such study would not be comparable with that in the three other groups shown in table 3 . Therefore, we did not include results related to this group in table 4.

As to the groups in which the BAL was investigated, the results considered above again justify the conclusion that the observed intergroup differences in the BAL cytology are due not to a dust overload as such but to the severity of the silicotic process induced by it, which in turn corresponds to the AI value. This process takes place mainly in the pulmonary interstices and begins with the phagocytosis of the penetrating silica particles by macrophages of the interstitial pool and with cytotoxic damage to these cells. This pool serves as the main source of AMs recruited to avleoli ${ }^{12}$ and it is logical to suppose that their recruitment may suffer when the damage reaches a certain level. The developing sclerosis of the alveolar septa may also, presumably, interfere with that recruitment.

It is possible to suppose that we deal here not only with inhibited recruitment of AMs but also with a greatly enhanced destruction of recruited AMs by the cytotoxic action of the silica particles phagocytosed on the free surface of the alveoli. Indeed, it was found earlier in our laboratory that during the course of long term inhalation exposure to quartz dust, the proportion of degenerated AMs in the BAL gradually increases. ${ }^{14}$ Later on we have shown that both the number of NLs in the BAL and the NL/AM ratio increase as the proportion of degenerated AMs increases in silica exposed or control rats, or in dose dependent manner after intratracheal instillation of PMB. ${ }^{12}$ Therefore one may surmise that in the experiment under consideration, a steady rise of both indices reflected the increase in the degeneration of AMs which at the end of the 40th week of exposure had reached such a degree that 24 hours after the last inhalation of dust it was impossible to find the AM count higher than in the controls.

A decrease in the resistance of AMs to the cytotoxic action of silica may, in its turn, be explained if we assume that this cell originated from the already dam- 
Table 5 Main cytological characteristics of bronchoalveolar lavage (BAL) of rats 24 hours after intratracheal instillation of different peritoneal macrophage culture supernatants $(\bar{X} \pm S \bar{x})$

\begin{tabular}{|c|c|c|c|c|c|}
\hline \multirow[b]{2}{*}{ Group of rats } & \multirow[b]{2}{*}{$\begin{array}{l}\text { Instilled supernatant after the } \\
\text { centrifuging of }\end{array}$} & & & & \multirow[b]{2}{*}{$\begin{array}{l}\text { Coefficient } \\
N L / A M\end{array}$} \\
\hline & & Total & $\begin{array}{l}\text { Alveolar macrophages } \\
\text { (AM) }\end{array}$ & $\begin{array}{l}\text { Neutrophil leukocytes } \\
(N L)\end{array}$ & \\
\hline $\begin{array}{l}\text { I } \\
\text { II } \\
\text { III } \\
\text { IV } \\
\text { V }\end{array}$ & $\begin{array}{l}\text { Macrophages } \\
\text { Macrophages incubated with zymosan } \\
\text { Macrophages incubated with PMB } \\
\text { PMB } \\
\text { Incubation medium }\end{array}$ & $\begin{array}{l}1.02 \pm 8 \cdot 13 \\
1.61 \pm 0.14^{\mathrm{x}} \\
1.98 \pm 0.30^{+} \S \\
1.22 \pm 0.12 \\
0.76 \pm 0.04^{+} \S\end{array}$ & $\begin{array}{l}0.66 \pm 0.12 \\
0.72 \pm 0.17 \\
0.95 \pm 0.15 \\
0.67 \pm 0.11 \\
0.52 \pm 0.05\end{array}$ & $\begin{array}{l}0.28 \pm 0.06 \\
0.64 \pm 0.14^{+} \\
0.82 \pm 0.13^{x_{\S}} \\
0.43 \pm 0.09 \\
0.17 \pm 0.04 \S\end{array}$ & $\begin{array}{l}0.424 \pm 0.113 \\
0.880 \pm 0.274 \\
0.865 \pm 0.065^{x} \\
0.643 \pm 0.142 \\
0.314 \pm 0.084 \S\end{array}$ \\
\hline
\end{tabular}

$+\mathbf{x}$ and ${ }^{\circ}$ Values that differ with statistical significance (with $\mathrm{p}$, correspondingly, $<0.05,<0.01$, and $<0.001$ ) from those of group I. $\S$ Values of the groups III and V significantly $(\mathrm{p}<0.05)$ different from corresponding values of group IV.

aged interstitial pool. It would be impossible to deny the possibility, however, that changes in cell resistance also reflect some general shift in the host's non-specific reactivity. It has been shown in our laboratory that on the one hand, the resistance of the AM to the cytotoxicity of silica in vivo could be predictably moderated by agents and factors influencing the host's general reactivity, ${ }^{1516}$ and on the other, that the latter underwent biphasic shifts on the background of the development of silicosis may, in turn, be decreasing when this development reached a sufficiently advanced stage. ${ }^{1718}$

The enhanced recruitment of NLs may, in turn, be due not only to the intensified breakdown of AMthat is, to the increase of endogenous PMB dose-but also to some changes in the host's ability to react to the PMB stimulus. For example, we showed earlier that the recruitment of NLs after intratracheal instillation of a fixed PMB dose increased against the background of the influence of a mineralocorticoid, or of cholinomimetic or adrenoblocking effects. ${ }^{2}$ In other words, one may suppose that the compensatory increase in recruitment of NLs observed in the present investigation was mediated not only through self regulation but through neurohormonal regulatory mechanisms as well.

Having analysed retrospectively some earlier experimental data in the light of the present results, we found that they are in good agreement with the conjectures discussed above. For instance, in rats inhaling the same quartz dust although in a lower concentration $\left(47.9 \pm 2.9 \mathrm{mg} / \mathrm{m}^{3}\right)$ the $\mathrm{NL} / \mathrm{AM}$ ratio was 2.94 times as great as in control rats after 10 weeks, and 10.00 times after 33 weeks exposure. Still more pronounced was the change in a group exposed to the far more cytotoxic aerosol of colloid silicic acid (52.8 \pm $4.1 \mathrm{mg} / \mathrm{m}^{3}$ ): respectively, 7.06 and 31.50 times. $^{19}$ In the second group pulmonary silicon dioxide retention has not increased during the course of the investigation; it had reached a "plateau" level already by the 10th week of exposure, which fact corroborates our hypothesis of a constant clearance rate maintained by the increased contribution from the NLs.
Possibly the inhalation of amosite, ${ }^{45}$ which is less cytotoxic than silica, produces a smaller amount of PMB and, hence, induces a smaller recruitment of NLs. In addition, the small size of an NL probably renders it unable to engulf the fibres even of the length which does not hinder their phagocytosis by AM, and this eventually makes the compensation of NL for the degeneration of $\mathrm{AM}$ inadequate. It is also possible that the fibrous shape of asbestos particles mechanically hinders their elimination from fixed lung tissues and thus leads to the phenomenon of "sequestration" which was not observed after exposure to quartz dust. These explanations of the kinetic differences between amosite and quartz are, however, no more than speculative.

A cause effect relation between the enhancement of the degeneration of AMs in the lower airways and that of the recruitment of NLs we explained formerly by a direct NL attractant effect of PMB. This effect has been repeatedly shown in experiments with intratracheal injection of whole PMB or PMB supernatant and with resuspended lipids extracted from PMB and also in experiments in vitro which showed the stimulation of the mobility of both NLs and AMs in the presence of PMB. ${ }^{122021}$ Later, experimental results of American investigators became available which showed that activated alveolar macrophages are able to produce, or to release, a chemotactic factor for human blood neutrophils. ${ }^{2-24}$ We had accumulated many experimental data suggesting that PMB activate a viable macrophage ${ }^{192025}$ and we supposed ${ }^{2}$ that the preferential recruitment of NLs to the airways might be due not only to the above mentioned attractant action of PMB themselves but also to the PMB influencing viable AMs so as to make them produce or release a specific NL attractant.

As seen from table 5, the activation of peritoneal macrophages with zymosan in vitro carried out under the same condition as in the experiments of the American authors ${ }^{2324}$ resulted in a significant increase in the ability of the cellular culture's supernatant instilled intratracheally to recruit NLs into the airways, but this activation did not influence the 
recruitment of AMs. One may conclude that the ability of an activated cell to produce an NL attractant is characteristic not only of the alveolar but also of the peritoneal macrophage, and that this ability may be shown not only with in vitro experiments modelling chemotaxis $^{22-24}$ but also with intratracheal instillation of macrophageal supernatant.

The supernatant of PMB, as in our earlier experiments, induced the recruitment of phagocytic cells into airways with an increased NL/AM ratio (table 5). Greater shifts in the same direction were induced with the supernatant of viable macrophages preincubated with the same PMB dose, this response being also significantly stronger than that of the supernatant of macrophages preincubated without PMB. The cellularity of the BAL and the NL/AM ratio after instillation of the latter did not differ significantly from those after instillation of a control incubation medium. (Resting macrophages do not produce an NL attractant and their breakdown during preincubation and centrifuging was evidently not sufficient to give the same effect as PMB.)

Taken as a whole, the results of this experiment seem to be in good agreement with our hypothesis of the production or release of an NL attractant by PMB activated viable macrophages.

\section{References}

1 Privalova LI, Katsnelson BA, Osipenko AV, Yushkov BH, Babushkina LG. Response of a phagocyte cell system to products of macrophage breakdown as a probable mechanism of alveolar phagocytosis adaptation to deposition of particles of different cytotoxicity. Environ Health Perspect 1980;23:205-18.

2 Katsnelson BA, Privalova LI. Recruitment of phagocytizing cells into the respiratory tract as a response to the cytotoxic action of deposited particles. Environ Health Perspect 1984;55:313-25.

3 Stöber W, Einbrodt MJ, Klosterköter W. Quantitative studies of dust retention in animal and human lungs after chronic inhalation. In: Davis CV, ed. Inhaled particles and vapours II. Oxford: Pergamon Press, 1967:409-17.

4 Bolton RE, Vincent JN, Jones AD, Addison J, Beckett ST. An overload hypothesis for pulmonary clearance of UICC amosite fibres by rats. $\mathrm{Br} J$ Ind $\mathrm{Med}$ 1983;40:264-72.

5 Vincent JH, Johnson AM, Jones AD, Bolton RE, Addison J. Kinetics of deposition and clearance and inhaled mineral dusts during chronic exposure. Br J Ind Med 1985;42:707-15.

$6 \mathrm{LaBelle} \mathrm{CW}$, Brieger $\mathrm{H}$. The fate of inhaled particles in the early postexposure period. II. The role of pulmonary phagocytosis. Arch Environ Health 1960;1:423-7.

7 Katsnelson BA, Babushkina LG, Velichkovski TB. Changes of total lipids content in lungs of rats in experimental silicosis. Byulleten Experimentalnoj Biologii i Mediciny 1964;N6:49-54.*

8 Chvapil M. Möglichkeiten einer quantitativen Bestimmung des Fibrosegrades bei der Untersuchung experimenteller Silikose. Beitrage zur Silikoseforschung 1960;64:3-71.

9 Stacy CD, King EJ. Silica and collagen in the lungs of silicotic rats treated with cortisone. $\mathrm{Br} J$ Ind Med 1954;11:192-8.
$10 \mathrm{King}$ EJ, Belt T. The physiological and pathological aspects of silica. Physiol Rev 1938;18:329-56.

11 Baidosov VA, Katsnelson BA, Privalova LI. An approach to the mathematical analysis of the pattern optimisation of shortening the cumulative working period under exposition to harmful substances with marked cumulative ability, taking pulmonary dust retention as an example. In: Mazurov VD, Smirnov AI, eds. Mathematical models of biological and medical systems. Sverdlovsk: Urals Scientific Centre, (in press). ${ }^{*}$

12 Bowden DH, Adamson IYR. The pulmonary interstitial cells as immediate precursor of the alveolar macrophage. Am J Pathol 1972;68:521-8.

13 Brain JD. Macrophages in the respiratory tract. In: Fishman AP, Fisher AB, eds. Handbook of physiology. Section 3. The respiratory system. Vol 1. Circulation and nonrespiratory functions. Bethesda: American Physiological Society, 1985:447-71.

14 Rusyaeva LV, Babushkina LG, Katsnelson BA. A further study of some mechanisms of the influence of fat and muscle stress on silicosis development. In: Domnin SG, Katsnelson BA, eds. Occupational diseases of dust aetiology. Vol 4. Moscow: Erisman Institute of Hygiene, 1977: 115-26.

15 Starikova SK, Katsnelson BA. On the influence of some factors on the pattern and efficiency of the alveolar phagocytosis of quartz dust. Gig Truda 1970;10:48-50.*

$16 \mathrm{Katsnelson}$ BA. On some mechanisms of combined action taking parts in aethiopathogenesis of silicosis. In: Velichkovski BT, ed. Combined action of chemical and physical factors of workingroom environment. Sverdlovsk: Institute of Industrial Hygiene and Occupational Diseases, 1972:10-9.*

17 Varzina NV, Katsnelson BA, Kashkin KP. On the antigenic changes in lungs and their role in the pathogenesis of experimental silicosis. In: Velichkovski BT, ed. Occupational diseases of dust aetiology. Vol 2. Moscow: Erisman Institute of Hygiene, 1974:81-95*

18 Petrova EV, Katsnelson BA, Privalova LI. An attempt of predicting the "susceptibility to silicosis" judging from the initial level of host's immune reactivity. In: Domnin SG, Katsnelson BA, eds. Occupational diseases of dust aetiology. Vol 4. Moscow: Erisman Institute of Hygiene, 1977:96-103.*

19 Katsnelson BA, Privalova LI, Kislitsina NS, Podgaiko GA. Correlation between cytotoxicity and fibrogenicity of silicosisinducing dusts. Med Lav 1984;75:450-62.

20 Privalova LI, Morosova KI, Osipenko AV, Katsnelson BA. Effects of macrophage breakdown products on the functional activity of macrophages. In: Domnin SG, Katsnelson BA, eds. Occupational diseases of dust aetiology. Moscow: Erisman Institute of Hygiene, 1980:50-7.*

21 Privalova LI, Katsnelson BA, Osipenko AV. Role of macrophage breakdown products in the alveolar phagocytosis response. Byulleten Experimentalnoj Biologii $i$ Mediciny 1977;83:393-6. (English translation.)

22 Hunninghake GW, Gallin JI, Fauci AS. The in vivo and in vitro generation of neutrophil chemotactic factor by alveolar macrophages. Am Rev Respirt Dis 1978;117:15-23.

23 Hunninghake GW, Gadek JE, Fales HM, Crystal R. Human alveolar macrophage-derived chemotactic factor for neutrophils. J Clin Invest 1980;66:473-83.

24 Gadek JE, Hunninghake GW, Zimmerman RL, Crystal RG Regulation of the release of alveolar macrophage-derived neutrophil chemotactic factor. Am Rev Respir Dis 1980; 121:723-33.

25 Morosova KI, Aronova GV, Katsnelson BA, et al. On the defensive action of glutamate against the cytotoxicity and fibrogenicity of quartz dust. Br J Ind Med 1982;39:244-52.

*In Russian. 